\title{
Grasping the hydra: the need for a holistic and systematic approach to disaster risk reduction
}

\section{Per Becker}

Visiting Professor at the Department of Fire Safety Engineering and Systems Safety Lund University, Sweden per.becker@brandt.ith.se

\section{ABSTRACT}

This article stresses the significance of recognising interdependencies between factors determining disaster risk in any attempts to integrate disaster risk reduction in international development cooperation. It bases its arguments on the case studies of four past projects in Sri Lanka and Tajikistan, which are scrutinised using a theoretical framework based on systems approaches. It appears that the results of ignoring interdependencies may (1) cause sub-optimisation problems where the desired outcome is not reached as the factor focused on and/or the desired outcome are dependent on other factors, and (2) make it difficult or impossible to monitor and evaluate the actual effects of international development cooperation projects in disaster risk reduction.

\section{KEYWORDS}

disaster risk reduction, systems approaches, complexity and interdependence.

\section{Introduction}

Disasters cause horrible consequences in human lives and suffering. The majority of the fatalities and instances of devastation occur in the developing parts of the world, posing a major threat to sustainable development and to the Millennium Development Goals (UNDP, 2004:9-27; UN Millennium Project, 2005). A growing number of donor agencies are recognising connections between disaster risk and poverty, and are currently drafting policies on how to further integrate disaster risk reduction into their official development assistance (e.g. DFID, 2006; Danish Ministry of Foreign Affairs, 2007). 
Disaster risk is a complex issue involving all spheres of society, i.e. the physical and environmental, the social and cultural, the political and the economic (ISDR, 2004:16; Wisner et al., 2004:49-84; Coppola, 2007:146-161; Boin, 2007:114129). This complexity of interdependent factors determining risk has been identified as a major obstacle to effective disaster risk reduction (Perrow, 2008:164165). One way to overcome this obstacle is to apply more holistic approaches that include a wider range of factors of disaster risk (e.g. McEntire, 2002; Cochard et al., 2008; Marvin et al., 2009). However, advocates of more holistic approaches to disaster risk do not give many indications of what the negative results are that may come if such approaches are not adhered to, which in turn could limit their persuasive influence on policy-makers for international development cooperation.

This article is an attempt to examine the need for holistic approaches to disaster risk in international development cooperation, by studying four recent projects in Sri Lanka and Tajikistan. The research question that the article attempts to answer is:

What general results may come from focusing international development cooperation on specific factors influencing disaster risk without acknowledging interdependencies with other factors?

The investigation starts with drawing up a theoretical framework asserting the complexity of disaster risk, introducing systems approaches as tools for grasping complexity and studying how these theoretical findings resonate with international guiding documents for integrating disaster risk reduction into international development cooperation. The following sections introduce the research methodology and methods used to answer the research question, as well as presenting the empirical findings. The article ends with a discussion of the findings and a presentation of its conclusions.

\section{The complexity of disaster risk}

Disasters are not discrete unfortunate events detached from everyday societal processes, but constructed over time and are closely linked with the development of society (Fordham, 2007:338-339). Irrespective of whether a disaster is triggered by a specific hazard, there are various interdependent factors influencing the hazard's frequency, intensity, location, duration, speed of onset, etc (Coppola, 2007:31-39). The susceptibility for being destructively affected by the hazard is also determined by a complex set of interdependent factors (Hearn Morrow, 1999; ISDR, 2004:16; Wisner et al., 2004:49-84; Coppola, 2007:146-161; Boin, 
2007:114-129), as is the capacity of individuals, organisations and societies at risk, to anticipate, avoid, cope with and recover from the disaster (Leveson et al., 2006). Disasters can thus rarely be sufficiently explained as results of linear chains of events, like dominos falling on each other, but are better understood as non-linear phenomena which emerge in complex systems of interrelated and interdependent conditions and events (Hollnagel, 2006:10-12). A disaster is here defined as a severe disruption of the functioning of a society causing extensive human, material, economic or environmental losses that exceed the ability of the affected society to manage using its own resources (ISDR, 2004:16). To substantially reduce disaster losses it is important to increase focus on reducing the risk of future disasters. There exists a multitude of expressions all describing risk in different ways. This article does not intend to use or produce such expressions, but states instead that risk is the answer to (1) what can happen, (2) how likely is it that that will happen and (3) if it does happen, what are the consequences (Kaplan and Garrick, 1981:12-13), regardless of what expression is used. However, the three components of hazard, vulnerability and capacity are often viewed as the building blocks of risk (e.g. Heijmans and Victoria, 2001:52-63; Cannon et al., 2003; Vermaak and Niekerk, 2004; Chen et al., 2007; Saldaña-Zorrilla, 2008) and need to be included in attempts to answer the three questions mentioned above.

Efforts to explain and understand, as well as to reduce disaster risk have had a tendency in the past to reduce the problem into parts that fit academic disciplines, professional sectors, organisational mandates, etc (Fordham, 2007). Such reductionist strategies may be effective when dealing with specific and wellbounded problems, but not with the complexity of real-world problems (Checkland, 1999:59-74; Senge, 2006:68-73). This kind of fragmented problem solving is instead likely to be a major weakness as it clouds the bigger picture of risk (Hale and Heijer, 2006:139). The challenge in reducing risk is thus not to find a way to divide the issue into parts that fit the mandate or agenda of specific stakeholders, but instead to grasp the dynamics and non-linear interdependencies between all parts in these complex systems of factors determining risk (Hollnagel, 2006:14-17). In other words, disaster risk is a complex issue not only because it includes factors from all spheres of society, but also because many of these factors are interdependent on each other. This complexity makes such systems difficult to understand (Cebulla, 2004:87), which is believed to be a main reason for why so few researchers have applied such multi-sectoral approaches in the past (Twigg, 2004:271). It is obviously impossible to understand such systems completely 
(Skyttner, 2005:100), but the goal must be to obtain as holistic a picture as possible (McEntire, 2002).

\section{Systems approaches and results when ignoring interdependencies}

Disaster risk is complex. However, it is not the only area in which complexity constitutes a daunting challenge to scientific inquiry. Living organisms, the brain, society, the climate, ecosystems and computers are only a few other examples. What scholars in these areas have in common is that they are focusing on something functioning as a whole but made up of a multitude of parts and processes. Living organisms are made up by the complex interaction of a myriad of cells, the brain is a vast network of neurals transmitting signals, society is made up by individuals and organisations, etc. Some of these scholars find that one way of managing and trying to learn from this complexity is to look upon their entity under study as a system, as von Bertalanffy (1960) did regarding the living organism, Ashby (1960) regarding the brain and Buckley (1968) regarding society. A system is here defined as "a group of interacting, interrelated, or interdependent elements forming a complex whole" (American Heritage Dictionary, 2000). Systems approaches are thus not only focusing on the elements per se, but also on the relationships between the elements, which are crucial in order to understand the system as a whole (Checkland, 1999; Skyttner, 2005).

There are many examples where systems approaches have been applied in the area of risk and disasters (e.g. Haimes, 1992; Haimes et al., 1995; Hollnagel, 2004; Dekker, 2006; Hale and Heijer, 2006; Hollnagel, 2006; Leveson et al., 2006; Perrow, 2008; Petersen and Johansson, 2008). However, it is hard to find any direct guidance regarding the research question in this specific literature. It turns out to be more fruitful to look at applications of systems approaches in other areas in the search for general results when focusing on specific factors without recognising interdependencies with other factors.

If efforts focus on specific factors in a system, but there is limited understanding of interdependencies within that system, there is a grave risk of sub-optimisation problems (Boland, 1981:115; Liu and Leung, 2002:341). A sub-optimisation problem can be described as a situation where a change in one factor does not generate the desired outcome in the system as the factor and/or the desired outcome are dependent on other factors that are not changed or even counterbalance the intended change. Sub-optimisation problems may even generate counterproductive results due to lack of recognition of interdependencies (e.g. Wisner et al., 2004:57-59). 
It is not only sub-optimisation problems that may arise with a lack of understanding of the interdependencies in systems, but also problems with monitoring and evaluating the actual effects of a deliberate change in the system. Monitoring and evaluation are vital for system effectiveness (Skyttner, 2005:53-54), but not if focused solely on the implementation of the project activity per se and not also on what effects it has in the system in total (Davies, 2004). Davies (2004; 2005) goes even further by indicating that it is difficult, if not impossible, to monitor and evaluate actual effects of projects without attempting to understand interdependencies within the system.

\section{Integrating disaster risk reduction in development cooperation}

When donor agencies are attempting to integrate disaster risk reduction into their official development assistance, it is important to acknowledge that risk is determined by a complex system of interdependent factors from all spheres of society. Guiding documents for such integration (i.e. ISDR, 2005; 2007; 2008) include a wide range of factors to address and activities to include in international development cooperation projects. However, these documents do not emphasise the importance of identifying and understanding the interdependencies between the different factors and activities. In the light of the two previous sections of this article, this lack of emphasis on interdependencies may decrease the potential effectiveness of stakeholders' efforts to reduce disaster risk. It may even be questionable whether any approach can be called holistic without acknowledging interdependencies.

\section{Methodology}

There are several methodologies that could be used to empirically answer the research question, but taking into consideration its context-dependent outline and the contemporary framework of the research, case study research stands out as particularly suitable (Flyvbjerg, 2001:67-73; Yin, 1994:4-9). The selected cases are four past international development cooperation projects, two post-Tsunami housing reconstruction projects in southern Sri Lanka, and two capacity development projects with Tsentrospas in Tajikistan. Tsentrospas is a governmental elite unit for all types of rescue operations.

The data were collected during three missions, one for the Swedish Red Cross (SRC) and one for the Swedish Rescue Services Agency (SRSA) to Sri Lanka and one for SRSA to Tajikistan. The methods for collecting data were observation and interviews (both formal and informal). A wide range of informants were 
selected for the purposes of the missions, some part of which was relevant to this study. The selection included potential beneficiaries of the projects, such as representatives of the local communities targeted by the housing reconstruction projects and local communities and local and regional authorities (mainly in the Kulyab and Kurgan Tube areas) potentially affected by disasters and in need of Tsentrospas assistance. It also included representatives of involved national authorities, UN agencies, the national Red Cross (Sri Lanka) and Red Crescent (Tajikistan) societies, the International Federation of Red Cross and Red Crescent Societies (IFRC), the International Committee of the Red Cross (ICRC, only in Sri Lanka), as well as international and national Non-Governmental Organisations. The interviews were qualitative and included many aspects of which only a part was related to the selected international development cooperation projects. The interviews with beneficiaries and with most other informants in Sri Lanka were informal, while the mission in Tajikistan allowed formal interviews. The informants among the beneficiaries were selected on the basis of convenience (Bernard, 1995:96), while all other informants were selected through purposive sampling to obtain informants from as wide a selection of stakeholders as possible (Bernard, 1995:95-96).

The data collected were then analysed qualitatively in order to obtain indications of the purpose, results and actual effects of the four projects being studied. Interviewing a wide range of informants gives an equally wide range of opinions, each with its own point of view. This cannot be called triangulation as such, but it still provides a qualitative increase in the possibility of producing a rich picture of the projects under investigation.

\section{Housing reconstruction in southern Sri Lanka}

After the Indian Ocean tsunami in 2004, the affected region experienced an unprecedented inflow of international assistance (Telford et al., 2006). The number of national and international relief and recovery organisations in the region proliferated and massive funds were not only available but had to be spent promptly (Telford et al., 2006). The Red Cross and Red Crescent Movement rapidly increased its resources to deal with the immense needs in various sectors, including sending livelihood experts to Sri Lanka in order to support the integration of livelihood issues into the overall programming (IFRC, 2008).

The researcher was sent to support livelihood programmes, mainly in the south and southeast (Kalutara, Galle and Matara) and in the capital of Colombo. 
The researcher later came back on a second mission to Sri Lanka, managing the initiation of a capacity development project together with the Road Development Authority (RDA), for the purpose of strengthening the then over-used capacity for post-disaster reconstruction of bridges. However, this time the focus of the work was put on the inland district of Kurunegala and in Colombo. During both periods in Sri Lanka many housing reconstruction programmes were visited. Most of the International Federation of the Red Cross and Red Crescent Societies' (IFRC) programmes functioned well, providing viable housing to tsunami affected families. Other organisations did not however always include an element of more comprehensive analyses to guide their programming, which in several cases resulted in interesting but rather unfortunate outcomes. Two of these ill-planned examples constitute the case studies in Sri Lanka. New and wellconstructed houses were erected in both cases, but one of these newly established communities was not equipped with a sewage and waste water system. The correct number of houses was built according to plan, but it would obviously have been insanitary to live there without large additional investments.

The other case had a sewage system, but many of the houses were designed without consulting the future occupants, resulting in inadequate size for the typical family in that area. There was also another challenge resulting from the benevolent idea of protecting people from future tsunamis by establishing the community inland, where land was more readily available. The problem here was that a large number of these families were headed by fishermen and had their entire livelihood base at the coast, resulting in many of them moving back and leaving or renting out the house provided.

\section{Capacity development in Tajikistan}

In March 2006, the UN system launched a team to assess the disaster response preparedness of Tajikistan. The purpose of the mission was to assist the authorities to develop the response preparedness of Tajikistan by assessing the national capacities to respond to natural and environmental disasters (OCHA, 2006). During this mission the researcher was in contact with and visited a wide range of stakeholders relevant to disaster preparedness in Tajikistan.

The researcher was received by the Tsentrospas, the elite unit for all types of rescue operations in Tajikistan, which is located in the capital of Dushanbe. During the time at Tsentrospas and in the discussions with representatives of the unit it became clear that they were very committed and proud to serve the people of 
Tajikistan. What also became apparent were the very limited capacities of the unit due to several reasons that will not be elaborated on here. However, Tsentrospas had been supported by several international organisations during the years before this study. An Austrian organisation had donated hydraulic equipment for rescuing people trapped in collapsed buildings and crashed vehicles, and an international Non-Governmental Organisation had supported a training programme for the staff. These two projects constitute the case studies in Tajikistan.

In the case of the hydraulic equipment, there was an obvious need for such support. However, it was equally obvious that not sufficient focus had been placed on identifying what other capacities were needed for the equipment to have any actual effect on the capacities of Tsentrospas. The equipment was donated without any attempt to ensure lasting capacities regarding how to use and maintain the equipment. The actual result of the efforts was that Tsentrospas, several years after obtaining the equipment, still had not used it. One may also question the actual effects of such a donation of hydraulic tools considering the lack of effective means and resources to transport the tools to the scenes of accidents, or of a robust system of notifying the unit to bring the equipment, etc. The list of interdependent conditions can be seen to be very long. Hence, the donated equipment did not generate any increased capacity for managing disasters, but only frustration among the devoted Tsentrospas staff.

Similar results came from the support for the training programme. The training programme was never institutionalised into the wider context of the training system in Tajikistan and died as soon as the international support ended. Therefore, even if the unit included individuals with better training for a while, it did not have any lasting effects due to the lack of refresher training and staff turnover. Both projects together with Tsentrospas had good intentions and required investments in financial and human resources. However, neither project had any real sustainable effect on the capacity of Tsentrospas as the activities focused on factors that were dependent upon other factors that were ignored.

\section{Discussion}

It is clear in all four cases that crucial factors for reaching the purposes of the projects were ignored and left out. The ineffectiveness of these projects illustrates what systems approaches call sub-optimisation problems, in which the specific issue of giving shelter to tsunami affected families in Sri Lanka and developing the technical capacity of Tsentrospas for heavy rescue in Tajikistan became the 
overriding focus, losing sight of the overall picture and what real effects the projects were intended to have. Without an understanding of what other factors were needed to achieve the intended purposes, it did not matter how well specific project activities were implemented.

The four projects also illustrate that if there is no understanding of the relations between the purpose, efforts (costs) and actual effects of a project, it is difficult to monitor and evaluate the effectiveness of the project, which is a second general outcome stipulated by systems approaches to complex cases where interdependencies are ignored. Going back to the examples from Sri Lanka and Tajikistan, it is quite clear that the focus of the monitoring and evaluation of these projects was on the implementation of the individual project activities and not on their intended effects.

With sub-optimisation problems and possibilities for monitoring and evaluation in mind, it appears that acknowledging interdependencies is a central requirement for the success of international development cooperation projects in disaster risk reduction. It is important to note, however, that these four projects were selected because of their ineffectiveness and there are obviously positive examples of international development cooperation around the world as well. It also seems that systems approaches may supply a useful analytical framework for grasping the complexity of interdependent factors determining disaster risk, which would benefit from further inquiry.

\section{Conclusion}

So, what general results may arise from focusing international development cooperation on specific factors influencing disaster risk without acknowledging interdependencies with other factors? This study is obviously insufficient to claim to have an absolute answer to such a complex question. However, it seems that the results of ignoring interdependencies can be categorised into at least two general categories:

1. Not acknowledging interdependencies may cause sub-optimisation problems where the desired outcome is not reached as the factor focused on and/or the desired outcome are dependent on other factors that are ignored.

2. Not acknowledging interdependencies makes it difficult or impossible to monitor and evaluate the actual effects of international development coopera tion in disaster risk reduction.

It is recommended that emphasis be given to the significance of analysing and 
understanding interdependencies between factors determining disaster risk in any attempts to integrate disaster risk reduction in international development cooperation. A starting point would be to emphasise this in future international guiding documents for such integration, further facilitating holistic and systematic approaches to disaster risk reduction.

\section{References}

AMERICAN HERITAGE DICTIONARY. 2000. www.bartleby.com/61/ Date of access: 21 Sept. 2007.

ASHBY, W.R. 1957. An Introduction to Cybernetics. 2nd impression. London: Chapman \& Hall Ltd.

BERNARD, H.R. 1995. Research Methods in Anthropology. 2nd ed. Walnut Creek: AltaMira Press.

BOIN, B. 2007. Race, Class, Ethnicity, and Disaster Vulnerability. (In Rodríguez, H; Quarantelli, E.L. \& Dynes, R, eds. Handbook of Disaster Research. New York: Springer.) BOLAND, R.J. 1981. A Study in System Design: C. West Churchman and Chris Argyris, Accounting. Organizations and Society, 6(2):109-118.

BUCKLEY, W.F. 1968. Society as a complex adaptive system. (In Buckley, W.F. ed. Modern systems research for the behavioral scientist: A sourcebook. Chicago: Aldline Publishing.)

CANNON, T., TWIGG, J. \& ROWELL, J. 2003. Social vulnerability, sustainable livelihoods and disasters. London: Department for International Development.

CEBUlLA, M. 2004. Modeling Concepts for Safety-Related Requirements in Sociotechnical Systems. (In Heisel, M et al. eds. SAFECOMP 2004, Berlin \& Heidelberg: Springer-Verlag.)

CHECKLAND, P. 1999. Systems Thinking, Systems Practice. Chichester: John Wiley and Sons Ltd.

CHEN, S.C., WU, C.Y. \& KO, Y.C. 2007. Risk assessment of debris flow disaster in songhe village in taiwan. (In Geophysical research abstracts. Paper read at GRA conference held in Vienna on 15-20 April 2007. Vienna.)

COCHARD, R., RANAMUKHAARACHCHI, S.L., SHIVAKOTI, G.P., SHIPIN, O.V., EDWARDS, P.J. \& SEELAND, K.T. 2008. The 2004 tsunami in aceh and southern thailand: A review on coastal ecosystems, wave hazards and vulnerability. Perspectives in Plant Ecology, Evolution and Systematics, 10(1):3-40.

COPPOLA, D.P. 2007. Introduction to International Disaster Management. Oxford: Butterworth-Heinemann (Elsevier). 
DANISH MINISTRY OF FOREIGN AFFAIRS. 2007. Disaster Risk Reduction in Danish Development and Humanitarian Assistance. Vol. I-III. Copenhagen: Danish Ministry of Foreign Affairs.

DAVIES, R. 2004. Scale, Complexity and the Representation of Theories of Change. Evaluation, 10(1):101-121.

DAVIES, R. 2005. Scale, Complexity and the Representation of Theories of Change Part II. Evaluation, 11(2):133-149.

DEKKER, S. 2006. The field guide to understanding human error. Aldershot and Burlington: Ashgate.

DFID. 2007. Reducing the Risk of Disasters - Helping to Achieve Sustainable Poverty Reduction in a Vulnerable World. London: Department for International Development.

FLYVBJERG, B. 2001. Making Social Science Matter: Why social inquiry fails and how it can succeed again. Cambridge: Cambridge University Press.

FORDHAM, M. 2007. Disaster and development research and practice: A necessary eclecticism?. (In Rodríguez, H; Quarantelli, E.L. \& Dynes, R, eds. Handbook of Disaster Research. New York: Springer.)

HAIMES, Y.Y. 1992. Sustainable development: A holistic approach to natural resource management. IEEE Transactions on Systems, Man and Cybernetics, 22(3):413-417.

HAIMES, Y.Y., LAMBERT, J., LI, D., SCHOOFF, R. \& TULSANI, V. 1995. Hierarchical holographic modeling for risk identification incomplex systems. (Paper presented at 1995 IEEE international conference on systems, man and cybernetics held in Vancouver on 22-25 October 1995. Vancouver.)

HALE, A. \& HEIJER, T. 2006. Is resilience really necessary? The case of railways. (In Hollnagel, E., Woods, D.D. \& Leveson, N. eds. Resilience engineering: Concepts and precepts. Aldershot and Burlington: Ashgate.)

HEARN MORROW, B. 1999. Identifying and mapping community vulnerability. Disasters, 23(1):1-18.

HEIJMANS, A. \& VICTORIA, L.P. 2001. Citizenry-Based \& development-oriented disaster response. Quezon City: Center for Disaster Preparedness. http://www.cdp.org. ph/pubs/cbdodr-cdp.pdf Date of access: 3 Feb. 2009.

HOLLNAGEL, E. 2004. Barriers and accident prevention. Aldershot \& Burlington: Ashgate.

HOLLNAGEL, E. 2006. Resilience - the challenge of the unstable. (In Hollnagel, E., Woods, D.D. And Leveson, N. eds. Resilience engineering: Concepts and precepts. Aldershot \& Burlington: Ashgate.)

IFRC. 2008. Tsunami Four-Year Progress Report. Geneva: International Federation of Red Cross and Red Crescent Societies. 
ISDR. 2004. Living with Risk: A global review of disaster reduction initiatives. New York: United Nations Publications.

ISDR. 2005. Hyogo Framework for Action 2005-2015: Building the Resilience of Nations and Communities to Disasters. http://www.unisdr.org/wcdr/intergover/officialdoc/L-docs/Hyogo-framework-for-action-english.pdf Date of access: 20 Sept. 2007.

ISDR. 2007. Words Into Action: A Guide for Implementing the Hyogo Framework. Geneva: United Nations.

ISDR. 2008. Towards National Resilience. Geneva: United Nations.

KAPLAN, S. And GARRICK, B.J. 1981. On the quantitative definition of risk. Risk Analysis, 1(1):11-27.

LEVESON, N., DULAC, N., ZIPKIN, D., CUTCHER-GERSHENFELD, J., CARROL, J. And BARRET, B. 2006. Engineering resilience into safety-critical systems. (In Hollnagel, E., Woods, D.D. And Leveson, N. eds. Resilience engineering: Concepts and precepts. Aldershot \& Burlington: Ashgate.)

LIU, A.M.M. And LEUNG, M. 2002. Developing a soft value management model. International Journal of Project Management, 20(5):341-349.

MARVIN, H.J.P., KLETER, G.A., FREWER, L.J., COPE, S., WENTHOLT, M.T.A. And ROWE, G. 2009. A working procedure for identifying emerging food safety issues at an early stage: Implications for European and international risk management practices. Food Control, 20(4):345-356.

McENTIRE, D.A. 2002. A Comparison of Disaster Paradigms: The Search for a Holistic Policy Guide. Public Administration Review, 62(3):267-281.

OCHA. 2006. Disaster Response Preparedness in Tajikistan. http://www.unep.or.jp/ietc/ dm/Final_Report_UNDAC_Tajikistan.pdf Date of access: 15 Feb. 2008.

PERROW, C.B. 2008. Complexity, Catastrophe, and Modularity. Sociological Inquiry, 78(2):162-173.

PETERSEN, K.E. And JOHANSSON, H. 2008. Designing resilient critical infrastructure systems using risk and vulnerability analysis. (In Hollnagel, E., Nemeth, C.P. And Dekker, S. eds. Resilience engineering perspectives: Remaining sensitive to the possibility of failure. Aldershot \& Burlington: Ashgate.)

SALDAÑA-ZORRILLA, S. 2008. Stakeholders' views in reducing rural vulnerability to natural disasters in southern mexico: Hazard exposure and coping and adaptive capacity. Global Environmental Change, 18(4):539-542.

SENGE, P.M. 2006. The Fifth Discipline: The Art And Practise of the Learning Organisation, 2nd ed. London \& New York: Currency And Doubleday

SKYTTNER, L. 2005. General Systems approaches: Problems, Perspectives, Practice. 2nd ed. Singapore: World Scientific Publishing Ltd. 
TELFORD, J., COSGRAVE, J. And HOUGHTON, R. 2006. Joint evaluation of the international response to the indian ocean tsunami: Synthesis report. London: Tsunami Evaluation Coalition.

TWIGG, J. 2004. Disaster Risk Reduction: Mitigation and preparedness in development and emergency programming. Good Practice Review No.9. London: Overseas Development Institute.

UN MILLENNIUM PROJECT. 2005. Investing in Development: A Practical Plan to Achieve the Millennium Development Goals. London: Earthscan.

UNDP. 2004. Reducing Disaster Risk: A Challenge for Development. New York: John Swift Print Co.

VERMAAK, J. And VAN NIEKERK, D. 2004. Disaster risk reduction initiatives in south africa. Development Southern Africa, 21(3):555-574.

VON BERTALANFFY, L. 1968. General Systems Theory: Foundations, Development, Applications. New York: George Braziller.

WISNER, B., BLAIKIE, P., CANNON, T. And DAVIS, I. 2004. At Risk: Natural hazards, people's vulnerability and disasters, 2nd ed. London: Routledge.

YIN, R.K. 1994. Case Study Research. 2nd ed. London: Sage. 